\title{
ФЕНОТИПИЧЕСКИЙ СОСТАВ Т-ЛИМФОЦИТОВ КРОВИ В ДИНАМИКЕ РАДИОЙОДТЕРАПИИ С ИСПОЛЬЗОВАНИЕМ ФИКСИРОВАННОЙ АКТИВНОСТИ 1311 У ПАЦИЕНТОВ С БОЛЕЗНЬЮ ГРЕЙВСА
}

\author{
Дудина М.А., Фомина Д.В., Догадин С.А., Савченко А.А., Гвоздев И.И., Чанчикова Н.Г. \\ ФГБОУ ВО «Красноярский государственный медичинский университет имени профессора В.Ф. Войно-Ясенецкого» \\ Минздрава России, Красноярск, Россия \\ ФГБНУ Федеральный исследовательский центр «Красноярский научный чентр Сибирского отделения Российской \\ академии наук», обособленное подразделение «НИИ медицинских проблем Севера», Красноярск, Россия \\ КГБУз «Краевая клиническая больнича», Красноярск, Россия
}

ЦЕЛЬ: изучить фенотипический состав Т-лимфоцитов в периферической крови у больных болезнью Грейвса (БГ) до и через 1 месяц после радиойодтерапии (РЙТ) с использованием фиксированной активности ${ }^{131}$ I.

МАТЕРИАЛЫ И МЕТОДЫ: В исследование включено 36 Женщин, с верифицированным диагнозом БГ, из них 10 (27.7\%) с манифестным гипертиреозом и 26 (72.2\%) с рецидивом заболевания, средний воз-

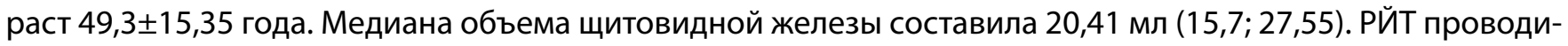
лась на базе отделения радионуклидной терапии Федерального Сибирского научно-исследовательского центра ФМБА России г. Красноярска. Всем пациентам назначалась фиксированная активность ${ }^{131}$ I от 400 до 700 МБк. Медиана уровня ТТГ, свободного тироксина (св.Т4) и свободного трийодтиронина (св.Т3) у обследуемых больных до РЙТ составила соответственно 0,03 мЕД/мл $(0,005 ; 0,54), 15,57$ пмоль/л $(11,42 ; 20,41)$ и 6,8 пмоль/л $(4,02 ; 8,5)$, а содержание АТ к рТТГ - 28,01 ME/л $(2,81 ; 35,7)$. Методом проточной цитометрии проводилось исследование фенотипического состава Т-лимфоцитов с использованием прямой иммунофлуоресценции цельной периферической крови.

РЕЗУЛЬТАТЫ: При исследовании иммунологических показателей обнаружено, что до РЙТ в периферической крови больных БГ относительно показателей контрольной группы снижено количество активированных общих Т-лимфоцитов $\left(\mathrm{CD} 3^{+} \mathrm{CD} 25\right)$, цитотоксических Т-клеток $\left(\mathrm{CD} 3^{+} \mathrm{CD} 8^{+}\right)$, при повышении Т-хелперов (CD3+CD4 $\left.{ }^{+}\right)$и активированных цитотоксических Т-лимфоцитов (CD3 $\left.{ }^{+} \mathrm{CD} 8^{+} \mathrm{CD} 25^{+}\right)$. Через месяц после РЙТ у больных БГ относительно контроля сохранялись пониженными $\mathrm{CD}^{+} \mathrm{CD} 8^{+}$. При сравнительной оценке показателей больных БГ в динамике после РЙТ выявлено снижение уровней $\mathrm{CD} 3^{+} \mathrm{CD} 4^{+} \mathrm{CD} 25^{+}-$ и $\mathrm{CD} 3^{+} \mathrm{CD}{ }^{+} \mathrm{CD} 25^{+}$-клеток. Количество Т-регуляторных клеток (Treg, CD3+CD4+CD127 ${ }^{\text {Low }} \mathrm{CD} 25^{\text {High }}$ ) у больных БГ изменялось только через месяц после РЙТ, с увеличением соответствующих показателей как относительно контроля, так и значений, установленных до РЙТ.

\section{ВЫводы.}

1. У больных БГ до РЙТ в периферической крови снижено количество активированных общих Т-лимфоцитов, цитотоксических Т-клеток, при повышении Т-хелперов и активированных цитотоксических Т-лимфоцитов.

2. Через 1 месяц после РЙТ у больных БГ в периферической крови наблюдается изменение соотношения субпопуляций Т-лимфоцитов в сторону значительного повышения Treg, при снижении активированных цитотоксических Т-клеток и Т-хелперов.

3. Дальнейшее изучение фенотипического состава лимфоцитов у больных БГ в исходе РЙТ позволит не только оценить влияния радиоактивного йода на аутоиммунный процесс, но и персонализировать подход к использованию радионуклидного метода в лечении заболевания.

КЛЮЧЕВЫЕ СЛОВА: болезнь Грейвса, тиреотоксикоз, Т-лимфоциты периферической крови, радиойодтерапия, фиксированная активность 1311. 